\title{
An exploration of the knowledge structure in studies on old people physical activities in Journal of Exercise Rehabilitation: by semantic network analysis
}

\author{
Sang-Wan Jeon', Ji-Youn Kim²,* \\ 'Exercise Rehabilitation Convergence Institute, Gachon University, Incheon, Korea \\ 2Department of Exercise Rehabilitation \& Welfare, College of Health Science, Gachon University, Incheon, Korea
}

Physical activity, a key component of maintaining health, is becoming an essential alternative in reducing medical expenses for the old people. This research was intended to analyze 51 research papers published in the Journal of Exercise Rehabilitation (JER) through semantic network analysis. The subjects of the study were the keywords that the authors of each paper used in journal search sites from 2013 to 2019. The present researcher analyzed the frequency, density, and centrality of the keywords of the indicators through semantic network analysis and then visualized them on the basis of findings using UCINET6 and the NetDraw program. Also, the researcher classified the hidden clusters by CONCOR (Convergence of iterated Correlations) analysis, which is a kind of cluster analysis. As a result, it was found that the keyword with the highest frequency was "exercise," followed by "cognition, "physical-activity," "old-women," “Korean," "fall," and "training." It was also found that most of the high-frequency keywords, such as "exercise," "cognition," "old-women," "program" and "depression" had high centrality. These keywords were classified into four clusters: (a) mental health research, (b) physical health research, (c) social behavior research, and (d) leisure efficacy research. This suggests that the old people-related research papers published in the JER have derived effective methods of maintaining physical and mental health using scientific exercise programs, and especially address the effects of exercise intervention for old women.

Keywords: Semantic network analysis, Physical activity, Knowledge structure, Journal of Exercise Rehabilitation

\section{INTRODUCTION}

The Statistics Korea (2019) has reported that it is highly likely that Korea will become a "super-aged society" in 2025 due to a severe low birth rate and accelerated aging. As the median age, which was 42.0 years in 2017 , is expected to rise to 56.8 years, an increase of 14.8 years, during the next 30 years, it is urgently required to prepare heath care measures for the rapidly increasing old population.

As Korean society is rapidly transforming into a super-aged society, various attempts are being made in a variety of fields to prepare fundamental measures in response to the health problems of the old people. Above all, as physical activity has been scientifically proven to be an effective intervention tool for old people health care, it is being actively used as a national policy and other alternative means for reducing national health care expenses. In particular, reduction of muscle mass in the old people (Manini and Clark, 2012) may reduce their ability to perform daily activities, resulting in health problems (Scott et al., 2015), whereas the habit of exercising on a regular basis prevents aging and increases physical strength, thus reducing the incidence of disease (Ngandu et al., 2015). It also has a positive effect on the physical and mental health of the old people, such as preventing chronic diseases, improving physical function, increasing muscle strength, reducing depression, and relieving stress (Graham and Reid, 2000; Hicks et al., 2003). For these reasons, our society recommends and encourages the old people to exercise more. This social trend is considered a subject of great interest in the academic field, and relevant studies are be-
${ }^{*}$ Corresponding author: Ji-Youn Kim (D) https://orcid.org/0000-0003-2325-1921 Department of Exercise Rehabilitation \& Welfare, College of Health Science, Gachon University, 191 Hambangmoe-ro, Yeonsu-gu, Incheon 21936, Korea E-mail: eve14jiyoun@naver.com

Received: January 9, 2020 / Accepted: February 2, 2020
This is an Open Access article distributed under the terms of the Creative Commons Attribution Non-Commercial License (https://creativecommons.org/licenses/by-nc/4.0/) which permits unrestricted non-commercial use, distribution, and reproduction in any medium, provided the original work is properly cited. 
ing actively conducted (Jiang et al., 2020; Miller et al., 2019).

Traditionally, many studies on physical activity of the old people have been conducted with various approaches such as comparison, analysis, and verification of effects centered on health and disease both in natural and social sciences (Ensari et al., 2017; Peterson et al., 2009). In recent years, however, studies on the old people have been diversified in terms of research forms and methods according to the changing trends of knowledge, such as interdisciplinary convergent and combined studies, beyond single-level studies. Nevertheless, when looking at the trends in academic research on exercise by the old people in Korea, there is still considerable progress in specific subjects, with many dissertations and articles published in journals, whereas there are few studies on the research trends. More specifically, although a holistic view of "what physical activity and exercise have been identified as old people health intervention factors," "what areas need more improvement," and what "interests researchers have by the times" is required, the research on these characteristics is very limited. Therefore, it is very important to analyze the characteristics and forms of various studies on the physical activity of the old people according to the times. In addition, semantic network analysis, which can examine the relationship between each concept through structure and frequency analysis, as well as an analysis of how many specific concepts appear in a text, can identify other research trends, which is different from conventional research trend analysis.

Therefore, this research was conducted to analyze trends and the flow of knowledge in the elderly-related papers published in the Journal of Exercise Rehabilitation (JER) to investigate changes in the interests and analysis methods of researchers, thus providing information and implications for the academic knowledge system of old people physical activities through semantic network analysis. To achieve the purpose of this research, first, the keywords, the semantic connection of the keywords and the cluster characteristics of the keywords in the old people-related papers published in JER from 2013 to 2019.

\section{MATERIALS AND METHODS}

\section{Subjects for analysis and data collection}

This research was intended to analyze the trends in research on the physical activity of the old people using semantic network analysis methodology. To achieve the purpose of the research, papers with "elderly" in the title among the papers published in JER were selected as a population. The research subjects were selected and the data were collected on the basis of the following criteria
Table 1. Number of papers subject to analysis by year

\begin{tabular}{lcccccccc}
\hline Year & 2013 & 2014 & 2015 & 2016 & 2017 & 2018 & 2019 & Total \\
\hline No. of papers & 5 & 8 & 6 & 6 & 11 & 9 & 6 & 51 \\
\hline
\end{tabular}

and procedure.

First, a procedure for selecting the academic database (DB) for the collection of the studies on the physical activity of the old people was conducted. The selection of an academic DB is an important process for analyzing research trends ( $\mathrm{Li}$ and Zhao, 2015). This is because the contents and results of the research data to be examined vary depending on the method of selecting the academic DB. In this research, only the papers published in JER from 2013 to 2019 were selected as the DB. Second, to collect research on the physical activity of the old people in the selected academic DB, research data with the keyword "elderly" in the research title were collected. The research data search period was from 2013 to 2019, and the keywords in a total of 51 papers published in JER were selected as the final research subject data. Third, the data for the collected keywords were refined. During this process, conjunctions included in the keywords were removed and keywords representing the meanings of similar words and synonyms were integrated. In addition, general research terms were deleted, and keywords were arranged in consideration of spacing. The number of papers subject to analysis is listed in Table 1.

\section{Analytical method}

In this research, the keywords in the 51 papers selected as the final subjects were analyzed with the following procedure. First, research text data related to "the elderly" were collected from JER. Second, the collected data were reprocessed to delete, combine or unify unnecessary post-positions, keywords, and synonyms. Third, frequency analysis was conducted and a matrix was generated by analyzing keywords using Textom. Fourth, keyword density was calculated; centrality analysis and Convergence of iterated Correlations (CONCOR) analysis were conducted and a network was visualized using the UCINET6 program and NetDraw program. The specific research procedure is shown in Fig. 1. The main research method used in this research is semantic network analysis, a methodology that applies social network analysis intended to find a system structure by finding the relationships between components for communication messages. It is a useful research methodology for understanding the communication structure through shared meaning (Drieger, 2013). Semantic network analysis is used for various terms, such as text network analysis (Sabot et al., 2017). The keyword extraction program used in this research was 

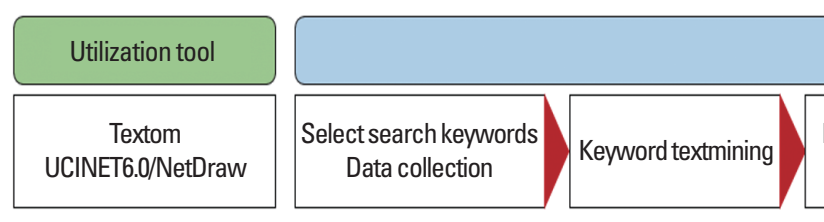

Analytical processes

Fig. 1. Research procedure. CONCOR, Convergence of iterated Correlations.

Textom, which was developed on the basis of the Korean Key Words in Context (KrKwic) program, a Korean text analysis software developed by Park et al. (2005). Textom is a big data processing solution that automatically collects data from various Internet channels by channel, refines them, and generates a matrix with a batch process. Next, analytic technology's UCINET6 was used to identify the structure of linkage between words and to analyze the degree centrality, thus quantifying the degree of relationship. In addition, for visualization, NetDraw was used to clearly express the relationships between words and to visualize the network between the keywords in the elderly-related papers. CONCOR analysis, which is intended to analyze the Pearson correlation of the co-occurrence matrix between words, identify blocks of nodes (keywords), and investigate the relationships between blocks, was used for structural analysis of the relationship between the hidden subclusters in the complicated network clusters (Li et al., 2019).

\section{Data integrity}

In this research, triangulation and peer consultation were conducted to secure data integrity. First of all, the present researcher used a peer consultation method to prevent the interpretation of the derived results from having an overly narrow perspective. To that end, the researcher consulted one doctor in sports health management, two doctors in sports sociology, and one expert in measurement and evaluation on an iterative manner. In this way, the objectivity of the research was secured and defects that might appear in the interpretation of the results were minimized.

\section{RESULTS}

\section{Extraction of keywords}

In this research, the keywords in the 51 papers with a title containing the word "elderly" that were published in JER from 2013 to 2019 were analyzed. The keywords are listed in Table 2 using Textom, a Korean text analysis program. For research question 1, the researcher analyzed the keywords in the elderly-related papers published in JER. As a result of analyzing the frequency of key-
Table 2. Frequency of keywords

\begin{tabular}{|c|c|c|c|c|c|}
\hline Rank & Keyword & Frequency & Rank & Keyword & Frequency \\
\hline 1 & Exercise & 28 & 19 & Factors & 3 \\
\hline 2 & Cognition & 13 & 19 & Muscle & 3 \\
\hline 3 & Physical-activity & 11 & 19 & Leisure & 3 \\
\hline 4 & Old-women & 9 & 19 & Body & 3 \\
\hline 5 & Korean & 9 & 19 & Resistance & 3 \\
\hline 6 & Fall & 8 & 31 & Sarcopenia & 2 \\
\hline 7 & Training & 8 & 31 & Visual & 2 \\
\hline 8 & Program & 7 & 31 & Status & 2 \\
\hline 9 & Aging & 6 & 31 & Dementia & 2 \\
\hline 9 & Strength & 6 & 31 & Frail & 2 \\
\hline 9 & Depression & 6 & 31 & Physical-performance & 2 \\
\hline 12 & Function & 5 & 31 & Pilates & 2 \\
\hline 12 & Social & 5 & 31 & Cardiovascular & 2 \\
\hline 14 & Physical & 4 & 31 & Hypertension & 2 \\
\hline 14 & Rehabilitation & 4 & 31 & Square & 2 \\
\hline 14 & Balance & 4 & 31 & Change & 2 \\
\hline 14 & Resilience & 4 & 31 & Experiences & 2 \\
\hline 14 & Mild & 4 & 31 & Participation & 2 \\
\hline 19 & Prevention & 3 & 31 & Efficacy & 2 \\
\hline 19 & $\begin{array}{r}\text { Activities-of- } \\
\text { daily-living }\end{array}$ & 3 & 31 & Obesity & 2 \\
\hline 19 & Bone & 3 & 31 & Frailty & 2 \\
\hline 19 & Composition & 3 & 31 & Risk-factors & 2 \\
\hline 19 & Impairment & 3 & 31 & Disability & 2 \\
\hline 19 & Combined & 3 & 31 & Stepping & 2 \\
\hline 19 & Behavior & 3 & 31 & Recovery & 2 \\
\hline
\end{tabular}

words, it was found that the most frequent keyword was "exercise" (28 times), followed by "cognition" (13 times), "physical-activity" (11 times), "old-women" (9 times), "Korean" (9 times), "fall” (8 times), "training" (8 times), "program" (7 times) and "aging" (6 times).

\section{Sematic network between keywords}

In the semantic network analysis, indicators that identify the characteristics of the network subject to analysis include "density," "degree" and "centrality" (Lu et al., 2018). Density is an indicator of how many relationships are between the nodes in the entire se- 


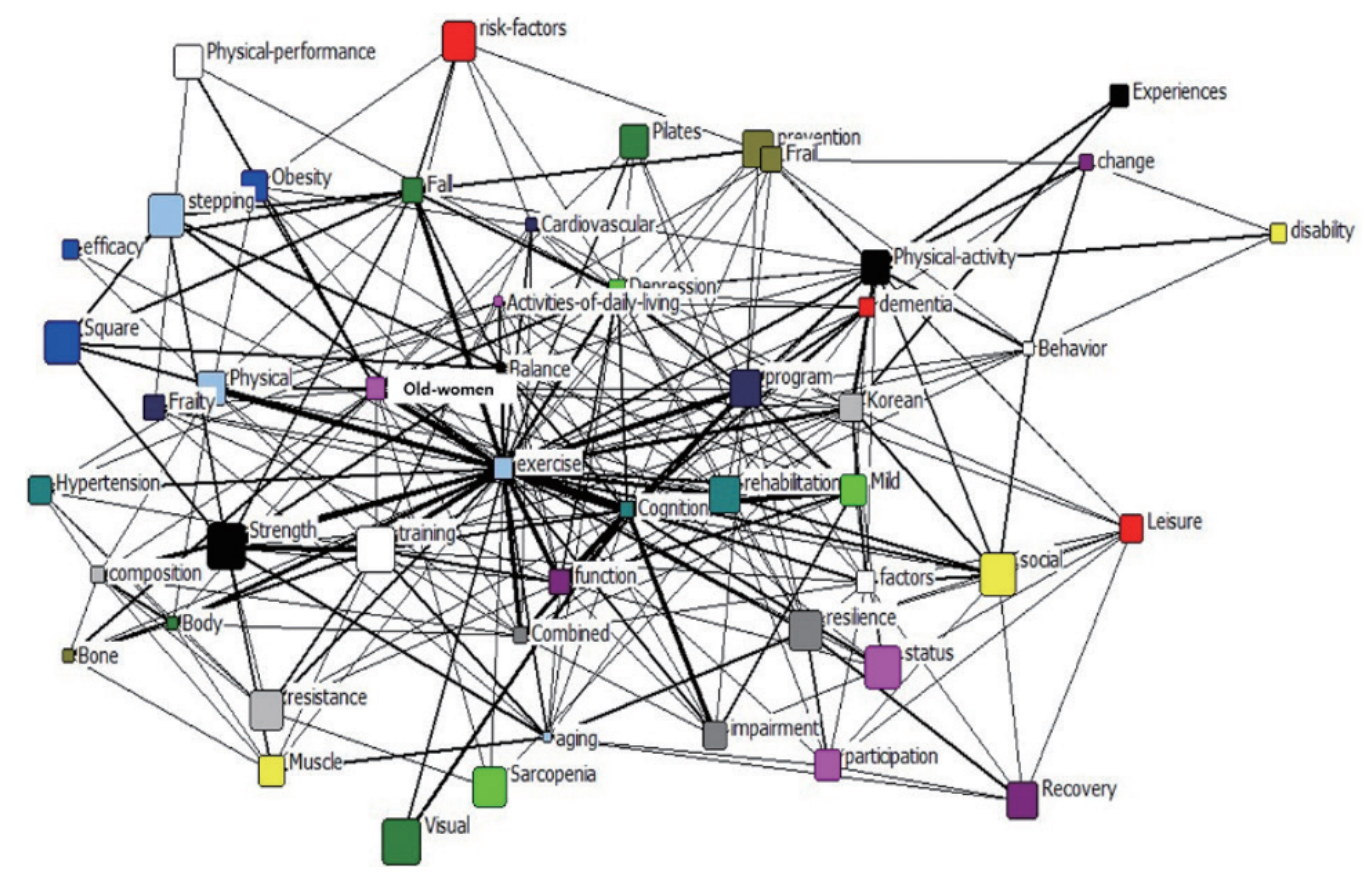

Fig. 2. Entire semantic network map.

Table 3. Density of the entire semantic network

\begin{tabular}{lccc}
\hline Density & $\begin{array}{c}\text { Connectivity } \\
\text { level }\end{array}$ & $\begin{array}{c}\text { Standard } \\
\text { deviation }\end{array}$ & $\begin{array}{c}\text { Mean connectivity } \\
\text { level by node }\end{array}$ \\
\hline 0.350 & 858 & 0.859 & 17.160 \\
\hline
\end{tabular}

Range of density: 0-1.

mantic network; degree is the number of other nodes (keywords) to which one node (keyword) is associated; and centrality is an indicator of how much each node constituting the semantic network is located in the center of the entire network. Centrality includes "degree centrality," "closeness centrality," and "between centrality" (Kang et al., 2017).

\section{Entire network of keywords}

In this research, the keywords that appeared more than twice in the 51 elderly-related papers published in JER, except for the search word "elderly," are nodes, and the connections between the nodes are "links" or "edges." The characteristics of the semantic network subject to analysis are in general expressed in the indicators, such as "density" and "degree" (Sadria et al., 2019). In this research, the density and degree of the semantic subject are as follows. In this research, the density of the semantic network was 0.350; the average degree of the keywords (each node) was 858; and the average degree was 17.160. The degrees can be presented by visualizing the entire semantic network using the NetDraw
Table 4. Degree centrality analysis results

\begin{tabular}{|c|c|c|c|c|c|}
\hline Keyword & Degree & nDegree & Keyword & Degree & nDegree \\
\hline Exercise & 117.000 & 0.239 & Factors & 16.000 & 0.033 \\
\hline Cognition & 59.000 & 0.120 & Muscle & 9.000 & 0.018 \\
\hline Physical-activity & 27.000 & 0.055 & Leisure & 10.000 & 0.020 \\
\hline Old-women & 30.000 & 0.061 & Body & 14.000 & 0.029 \\
\hline Korean & 27.000 & 0.055 & Resistance & 13.000 & 0.027 \\
\hline Fall & 25.000 & 0.051 & Sarcopenia & 4.000 & 0.008 \\
\hline Training & 34.000 & 0.069 & Visual & 6.000 & 0.012 \\
\hline Program & 35.000 & 0.071 & Status & 9.000 & 0.018 \\
\hline Aging & 18.000 & 0.037 & Dementia & 10.000 & 0.020 \\
\hline Strength & 24.000 & 0.049 & Frail & 7.000 & 0.014 \\
\hline Depression & 27.000 & 0.055 & Physical-performance & 4.000 & 0.008 \\
\hline Function & 28.000 & 0.057 & Pilates & 6.000 & 0.012 \\
\hline Social & 18.000 & 0.037 & Cardiovascular & 10.000 & 0.020 \\
\hline Physical & 17.000 & 0.035 & Hypertension & 8.000 & 0.016 \\
\hline Rehabilitation & 21.000 & 0.043 & Square & 10.000 & 0.020 \\
\hline Balance & 20.000 & 0.041 & Change & 7.000 & 0.014 \\
\hline Resilience & 16.000 & 0.033 & Experiences & 4.000 & 0.008 \\
\hline Mild & 23.000 & 0.047 & Participation & 9.000 & 0.018 \\
\hline Prevention & 9.000 & 0.018 & Efficacy & 4.000 & 0.008 \\
\hline $\begin{array}{r}\text { Activities-of- } \\
\text { daily-living }\end{array}$ & 13.000 & 0.027 & Obesity & 7.000 & 0.014 \\
\hline Bone & 8.000 & 0.016 & Frailty & 7.000 & 0.014 \\
\hline Composition & 14.000 & 0.029 & Risk-factors & 7.000 & 0.014 \\
\hline Impairment & 15.000 & 0.031 & Disability & 4.000 & 0.008 \\
\hline Combined & 19.000 & 0.039 & Stepping & 10.000 & 0.020 \\
\hline Behavior & 12.000 & 0.024 & Recovery & 7.000 & 0.014 \\
\hline
\end{tabular}


program, as shown in Fig. 2.

\section{Analysis of the centrality of keywords}

Semantic network analysis was conducted for the 50 words that appeared more than twice among the keywords in this research (Table 3). First, the researcher looked at the "degree centrality," "closeness centrality," and "betweenness centrality" in the top 50 keywords. In general, "centrality" is a measurement of how much each node is located in the center of the semantic network. As three representative indicators to measure the centrality of a node in a network, "degree centrality," closeness centrality" and "betweenness centrality" were presented (Prochnow et al., 2020). These three indicators are the most frequently used in network analysis, and contribute to the development of various types of centrality concepts and indicators (Kang et al., 2017; Sadria et al., 2019).

First, degree centrality, which shows how many links a node has with other nodes, is an ideal indicator for the measurement of "lo- cal centrality" (Prochnow et al., 2020; Taylor et al., 2017). Table 4 shows the degree centrality in the keyword network in the elderlyrelated papers published in JER. The degree centrality in the keyword network in the elderly-related papers was visualized using the NetDraw program. As a result of analyzing degree centrality, it was found that "exercise" had the highest degree centrality, followed by "cognition," "program," "training," "elderly-women," "function," "depression" "Korean," "physical-activity," and "Korean." In conclusion, the keywords with a high degree are centered to link other keywords.

Second, unlike degree centrality, closeness centrality, which shows the distance between indirectly linked nodes in addition to directly linked nodes, is a measure of centrality on the basis of the distance between nodes (Chen et al., 2013). The closeness centrality of the keyword network in the elderly-related papers published in JER is shown in Table 5. As a result of analyzing closeness centrality, it was found that the closeness to other nodes was highest

Table 5. Closeness centrality analysis results

\begin{tabular}{|c|c|c|c|c|c|c|c|}
\hline Keyword & FreeClo. & ValClo. & RecipClo. & Keyword & FreeClo. & ValClo. & RecipClo. \\
\hline Exercise & 0.875 & 0.952 & 0.929 & Factors & 0.570 & 0.748 & 0.629 \\
\hline Cognition & 0.662 & 0.830 & 0.745 & Muscle & 0.505 & 0.673 & 0.551 \\
\hline Physical-activity & 0.605 & 0.782 & 0.673 & Leisure & 0.476 & 0.633 & 0.551 \\
\hline Old-women & 0.628 & 0.803 & 0.711 & Body & 0.521 & 0.694 & 0.575 \\
\hline Korean & 0.605 & 0.782 & 0.673 & Resistance & 0.510 & 0.680 & 0.568 \\
\hline Fall & 0.563 & 0.741 & 0.619 & Sarcopenia & 0.505 & 0.673 & 0.531 \\
\hline Training & 0.598 & 0.776 & 0.670 & Visual & 0.476 & 0.633 & 0.497 \\
\hline Program & 0.653 & 0.823 & 0.735 & Status & 0.521 & 0.694 & 0.568 \\
\hline Aging & 0.551 & 0.728 & 0.612 & Dementia & 0.527 & 0.701 & 0.571 \\
\hline Strength & 0.533 & 0.707 & 0.595 & Frail & 0.533 & 0.707 & 0.568 \\
\hline Depression & 0.620 & 0.796 & 0.694 & Physical-performance & 0.430 & 0.558 & 0.466 \\
\hline Function & 0.583 & 0.762 & 0.656 & Pilates & 0.516 & 0.687 & 0.544 \\
\hline Social & 0.551 & 0.728 & 0.605 & Cardiovascular & 0.544 & 0.721 & 0.588 \\
\hline Physical & 0.538 & 0.714 & 0.605 & Hypertension & 0.500 & 0.667 & 0.548 \\
\hline Rehabilitation & 0.605 & 0.782 & 0.673 & Square & 0.495 & 0.660 & 0.531 \\
\hline Balance & 0.563 & 0.741 & 0.619 & Change & 0.430 & 0.558 & 0.480 \\
\hline Resilience & 0.557 & 0.735 & 0.616 & Experiences & 0.405 & 0.510 & 0.435 \\
\hline Mild & 0.551 & 0.728 & 0.612 & Participation & 0.516 & 0.687 & 0.565 \\
\hline Prevention & 0.538 & 0.714 & 0.571 & Efficacy & 0.485 & 0.646 & 0.510 \\
\hline Activities-of-daily-living & 0.563 & 0.741 & 0.619 & Obesity & 0.505 & 0.673 & 0.544 \\
\hline Bone & 0.505 & 0.673 & 0.544 & Frailty & 0.516 & 0.687 & 0.558 \\
\hline Composition & 0.521 & 0.694 & 0.575 & Risk-factors & 0.467 & 0.619 & 0.517 \\
\hline Impairment & 0.516 & 0.687 & 0.565 & Disability & 0.389 & 0.476 & 0.425 \\
\hline Combined & 0.570 & 0.748 & 0.629 & Stepping & 0.495 & 0.660 & 0.531 \\
\hline Behavior & 0.538 & 0.714 & 0.585 & Recovery & 0.422 & 0.544 & \\
\hline
\end{tabular}

FreeClo., condensation distance matrix that adds 1 to the longest distance observed in the network plus 1, the sum of the path distances of the individual nodes, reciprocal, and $\mathrm{N}-1$. It is calculated by multiplying; ValClo., average of the maximum path distance minus the path distances of the node pairs and is normalized based on the maximum possible value; RecipClo., inverse of the average. 
Table 6. Betweenness centrality analysis results

\begin{tabular}{|c|c|c|c|c|c|}
\hline Keyword & $\begin{array}{c}\text { Between- } \\
\text { ness }\end{array}$ & $\begin{array}{l}\text { nBetween- } \\
\text { ness }\end{array}$ & Keyword & $\begin{array}{c}\text { Between- } \\
\text { ness }\end{array}$ & $\begin{array}{c}\text { nBetween- } \\
\text { ness }\end{array}$ \\
\hline Exercise & 398.659 & 33.900 & Resistance & 5.917 & 0.503 \\
\hline Physical-activity & 78.432 & 6.669 & Frailty & 5.166 & 0.439 \\
\hline Old-women & 74.315 & 6.319 & Participation & 4.882 & 0.415 \\
\hline Program & 67.844 & 5.769 & Dtatus & 4.793 & 0.408 \\
\hline Cognition & 60.651 & 5.157 & Mild & 4.244 & 0.361 \\
\hline Depression & 53.437 & 4.544 & Composition & 3.551 & 0.302 \\
\hline Korean & 49.538 & 4.212 & Body & 3.551 & 0.302 \\
\hline Training & 27.734 & 2.358 & Muscle & 2.944 & 0.250 \\
\hline Rehabilitation & 26.414 & 2.246 & Risk-factors & 2.498 & 0.212 \\
\hline Fall & 25.279 & 2.150 & Obesity & 2.101 & 0.179 \\
\hline Aging & 20.144 & 1.713 & Change & 1.868 & 0.159 \\
\hline Behavior & 19.161 & 1.629 & Hypertension & 1.317 & 0.112 \\
\hline Factors & 18.366 & 1.562 & Impairment & 0.965 & 0.082 \\
\hline Resilience & 16.428 & 1.397 & Recovery & 0.806 & 0.069 \\
\hline Function & 15.000 & 1.275 & Sarcopenia & 0.781 & 0.066 \\
\hline Balance & 13.280 & 1.129 & Bone & 0.638 & 0.054 \\
\hline Physical & 13.036 & 1.109 & Square & 0.000 & 0.000 \\
\hline Combined & 12.496 & 1.063 & $\begin{array}{l}\text { Physical- } \\
\text { performance }\end{array}$ & 0.000 & 0.000 \\
\hline Social & 11.961 & 1.017 & Pilates & 0.000 & 0.000 \\
\hline Leisure & 11.175 & 0.950 & Experiences & 0.000 & 0.000 \\
\hline Strength & 10.123 & 0.861 & Dementia & 0.000 & 0.000 \\
\hline $\begin{array}{l}\text { Activities-of- } \\
\text { daily-living }\end{array}$ & 8.746 & 0.744 & Visual & 0.000 & 0.000 \\
\hline Cardiovascular & 6.761 & 0.575 & Disability & 0.000 & 0.000 \\
\hline Prevention & 6.033 & 0.513 & Stepping & 0.000 & 0.000 \\
\hline Frail & 5.965 & 0.507 & Efficacy & 0.000 & 0.000 \\
\hline
\end{tabular}

in "exercise," followed by "cognition," "program," "old-women," "depression," "physical-activity," "Korean," "rehabilitation," "training" and "function."

Third, betweenness centrality measures the degree to which a node is located "between" other points in the network. The more it is located on the geodesic, the higher the betweenness centrality of the node. In particular, keywords with high betweenness centrality are important in that even if they simply appear in the semantic network and the degree is low, it will be to communicate smoothly when they are excluded (Lee and Hong, 2013). The betweenness centrality of the keyword network in the elderly-related papers published in JER is shown in Table 6. As a result of analyzing betweenness centrality, it was found that "exercise" played the biggest role in mutually intervening and mediating keywords among other keywords, followed by "physical-activity," "old-women," "program," "cognition," "depression," "Korean," "training," "rehabilitation" and "fall." In conclusion, words such as "exercise," "cognition," "old-women," "program," "depression," "training," and "physical-activity," in general, appeared most frequently in degree centrality, closeness centrality and betweenness centrality, and are considered important subjects in the elderly-related papers published in JER.

\section{Results of CONCOR analysis}

As shown in Fig. 3, CONCOR analysis was conducted to ana-

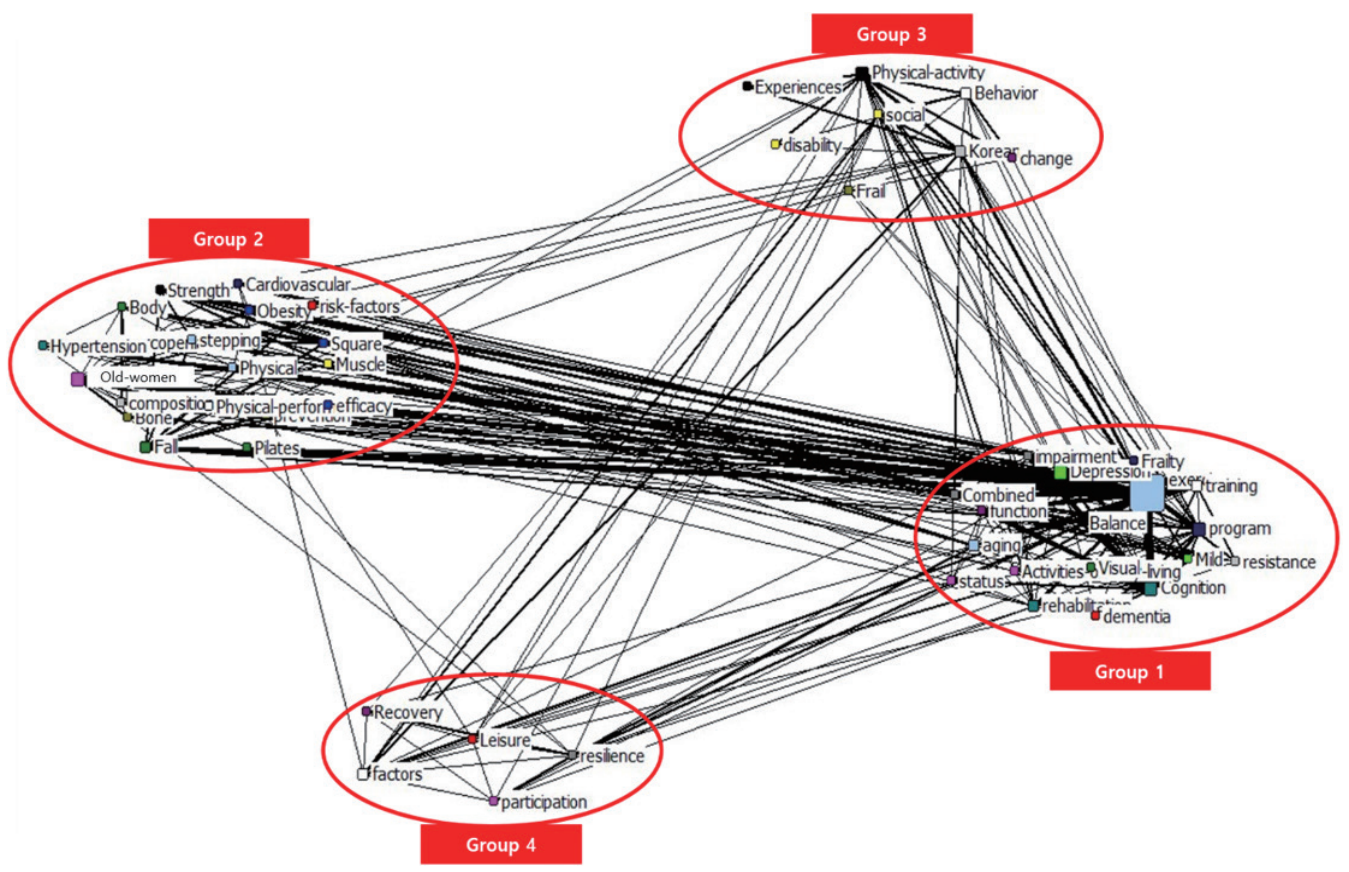

Fig. 3. Visualization of CONCOR (Convergence of iterated Correlations) analysis results. 
Table 7. Types of research based on CONCOR (Convergence of iterated Correlations) analysis

\begin{tabular}{lr}
\hline Cluster name & \multicolumn{1}{c}{ Keywords } \\
\hline Cluster 1: Mental health research & $\begin{array}{r}\text { Exercise, Cognition, Depression, Dementia, Aging, Frailty, Rehabilitation, Visual, Mild, Program, Impairment, Function, Activities-of- } \\
\text { daily-living, Combined, Status, Balance, Resistance, Training }\end{array}$ \\
Cluster 2: Physical health research & $\begin{array}{r}\text { Fall, Sarcopenia, Muscle, Obesity, Performance, Strength, Cardiovascular, Old-women, Pilates, Composition, Body, Bone, Physical, } \\
\text { Hypertension, Prevention, Risk-Factors, Efficacy, Square, Stepping }\end{array}$ \\
Cluster 3: Social behavior research & $\begin{array}{c}\text { Social, Change, Experience, Physical-Activity, Behavior, Disability, Korean } \\
\text { Cluster 4: Leisure efficacy research }\end{array}$ \\
\hline
\end{tabular}

lyze the characteristics of the semantic network of the elderly-related papers published in JER. As a result, keywords were classified into four subclusters, as shown in Fig. 3. The keywords by each subcluster are listed in Table 7. Cluster 1 is "mental health research," which includes words such as "exercise," "cognition," "depression," "dementia," "aging" and "frailty." Cluster 2 is "physical health research," which includes words such as "fall," "sarcopenia," "muscle," "obesity," "physical-performance," "strength," etc. Cluster 3 is "social behavior research," which includes words such as "social," "change," "experience," "physical-activity," etc. And Cluster 4 is "leisure efficacy research," which includes words such as "participation," "recovery," "resilience," and "leisure."

\section{DISCUSSION}

In this research, the present researcher analyzed research trends using the keywords in 51 papers published in JER (2013-19). The results of sematic network analysis of the research during the period can be summarized as follows:

First, as a result of analyzing the keywords in the papers published in JER, "exercise" appeared most frequently, followed by "cognition," "physical-activity," "old-women," "Korean,” "fall," "training," "program," "aging," "strength,” "depression," "function," and "social." This suggests that "exercise" is used most frequently as the keyword in the elderly-related papers published in JER. In other words, "exercise" is more frequently used to verify the exercise effect and to present various exercise methods as elderly health intervention factors. Prior research on rehabilitation and exercise for the elderly, factors associated with physical activity of women aged over 75 in South Korea (Suh and Kim, 2018); Effects of exercise and nutrition education programs on motor function and eating habit in mild dementia patients (Cho and Kim, 2019); and Exploring the field application of combined cognitivemotor program with mild cognitive impairment elderly patients (Kim, 2018) also reported that exercise is effective and improves cognition. Meanwhile, the semantic network density of the key- words in the 51 elderly-related papers published in JER was 0.350 , and the average degree of the keywords was about 17.160. This indicates that in high-density networks, the linkage between keywords is activated and various subjects are addressed. In the entire network, keywords such as "exercise, "cognition," "physical-activity" and "elderly," were located in the center of the entire semantic network, and these keywords were closely linked to other keywords in the papers published in JER.

Second, the sematic network centrality values of the elderly-related papers published in JER were analyzed and presented in the order of degree, closeness and betweenness centrality. First, for the top 10 degree centrality, "exercise" ranked first, followed by "cognition," "program," "training," "old-women," "function," "depression," "Korean," "physical-activity," and "Korean," indicating a high degree with other keywords. For the top 10 closeness centrality, "exercise" ranked first, followed by "cognition," "program," "old-women," "depression," "physical-activity," "Korean,” "rehabilitation," "training" and "function," indicating high closeness to other nodes both directly and indirectly. For the top 10 betweenness centrality, "exercise" ranked first, followed by "physical-activity," "old-women," "program," "cognition," and "depression," "Korean," "training," "rehabilitation," and "fall," indicating that they play the role of mutual intervention and mediation between other nodes. Therefore, it can be seen that the elderly-related research in JER is aimed to improve the physical and mental health of the old people as well as to prevent senile diseases by suggesting new programs through the verification of the effects and methods of exercise.

Third, as a result of conducting CONCOR analysis on the keywords in the 51 elderly-related papers published in JER, the keywords were divided into four subclusters. Cluster 1 with "exercise," "cognition," "depression," and "dementia" was named "mental health research.” Cluster 2 with "fall," "sarcopenia," "muscle," "obesity," "physical-performance," and "strength" was named "physical health research. Cluster 3 with "social," "change," "experience," "physical-activity," etc., was named "social behavior research." Clus- 
ter 4 with "participation," "recovery," "resilience," and "leisure," was named "leisure efficacy research." According to a report on elderly-related research, physical health (Hwang and Kim, 2015; Lee et al., 2020), mental health (Annesi, 2012), social ties (Miller et al., 2019), and leisure behaviors (Novais et al., 2019) are important factors due to the characteristics of aging. Likewise, the elderly-related research papers published in JER, the effect of 12-week Pilates exercises on wellness in the old people (Roh, 2016); Development and validation of exercise rehabilitation program for $\operatorname{cog}$ nitive function and activity of daily living improvement in mild dementia of old people (Choi et al., 2018); A Study of relationship between frailty and physical performance in elderly-women (Jeoung and Lee, 2015); Experience of sport stacking in Korean older adults have also considered these characteristics of the elderly (Park, 2017).

With regard to the limitations of this research, as only the papers published in JER were used for the purpose of analyzing trends in the research related to exercise for health by the elderly, there is a need to collect papers published in other renowned journals in an objective and scientific way to analyze research trends more closely. Old people-related papers were examined by summarizing the research trends in the old people-related papers published in JER through semantic network analysis. The implications derived from this research are expected to serve as basic data for presenting directions for follow-up studies.

\section{CONFLICT OF INTEREST}

No potential conflict of interest relevant to this article was reported.

\section{ACKNOWLEDGMENTS}

This work was supported by the Ministry of Education of the Republic of Korea and the National Research Foundation of Korea (NRF-2019S1A5A2A03037891).

\section{REFERENCES}

Annesi JJ. Contrast of biochemical and psychosocial explanations of the relationship of exercise and improved mood. Percept Mot Skills 2012; 114:693-697.

Chen DB, Gao H, Lü L, Zhou T. Identifying influential nodes in large-scale directed networks: the role of clustering. PLoS One 2013;8:e77455.

Cho MS, Kim JY. Effects of exercise and nutrition education programs on motor function and eating habit in mild dementia patients. J Exerc Re-

\section{habil 2019;15:88-94.}

Choi MR, Kim JY, Yi ES. Development and validation of exercise rehabilitation program for cognitive function and activity of daily living improvement in mild dementia elderly. J Exerc Rehabil 2018;14:207-212.

Drieger P. Semantic network analysis as a method for visual text analytics. Procedia - Soc Behav Sci 2013;79:4-17.

Ensari I, Kinnett-Hopkins D, Motl RW. Social cognitive correlates of physical activity among persons with multiple sclerosis: Influence of depressive symptoms. Disabil Health J 2017;10:580-586.

Graham A, Reid G. Physical fitness of adults with an intellectual disability: a 13-year follow-up study. Res Q Exerc Sport 2000;71:152-161.

Hicks AL, Martin KA, Ditor DS, Latimer AE, Craven C, Bugaresti J, McCartney N. Long-term exercise training in persons with spinal cord injury: effects on strength, arm ergometry performance and psychological well-being. Spinal Cord 2003;41:34-43.

Hwang HJ, Kim SH. The association among three aspects of physical fitness and metabolic syndrome in a Korean elderly population. Diabetol Metab Syndr 2015;7:112.

Jeoung BJ, Lee YC. A Study of relationship between frailty and physical performance in elderly women. J Exerc Rehabil 2015;11:215-219.

Jiang Y, Tan S, Wang Z, Guo Z, Li Q, Wang J. Aerobic exercise training at maximal fat oxidation intensity improves body composition, glycemic control, and physical capacity in older people with type 2 diabetes. J Exerc Sci Fit 2020;18:7-13.

Kang GJ, Ewing-Nelson SR, Mackey L, Schlitt JT, Marathe A, Abbas KM, Swarup S. Semantic network analysis of vaccine sentiment in online social media. Vaccine 2017;35:3621-3638.

Kim S. Exploring the field application of combined cognitive-motor program with mild cognitive impairment elderly patients. J Exerc Rehabil 2018;14:817-820.

Lee JM, Hong SJ. A study on the network of disabled person rehabilitation using social network analysis: focus on the comparison between two governments. J Exerc Rehabil 2013;9:536-543.

Lee SE, Park JH, Kim KA, Kang YS, Choi HS. Association Between Sarcopenic Obesity and Pulmonary Function in Korean Elderly: results from the Korean National Health and Nutrition Examination Survey. Calcif Tissue Int 2020;106:124-130.

Li J, Goerlandt F, Li KW. Slip and fall incidents at work: a visual analytics analysis of the research domain. Int J Environ Res Public Health 2019; 16:4972.

Li W, Zhao Y. Bibliometric analysis of global environmental assessment research in a 20-year period. Environ Impact Assess Rev 2015;50:158166.

Lu Z, Wahlström J, Nehorai A. Community detection in complex networks via clique conductance. Sci Rep 2018;8:5982. 
Manini TM, Clark BC. Dynapenia and aging: an update. J Gerontol A Biol Sci Med Sci 2012;67:28-40.

Miller KJ, Mesagno C, McLaren S, Grace F, Yates M, Gomez R. Exercise, mood, self-efficacy, and social support as predictors of depressive symptoms in older adults: direct and interaction effects. Front Psychol 2019;10:2145.

Ngandu T, Lehtisalo J, Solomon A, Levälahti E, Ahtiluoto S, Antikainen R, Bäckman L, Hänninen T, Jula A, Laatikainen T, Lindström J, Mangialasche F, Paajanen T, Pajala S, Peltonen M, Rauramaa R, StigsdotterNeely A, Strandberg T, Tuomilehto J, Soininen H, Kivipelto M. A 2 year multidomain intervention of diet, exercise, cognitive training, and vascular risk monitoring versus control to prevent cognitive decline in at-risk elderly people (FINGER): a randomised controlled trial. Lancet 2015;385:2255-2263.

Novais FV, Simoes EJ, Schmaltz C, Ramos LR. Randomized controlled trial of primary health care strategies for the promotion of leisure-time physical activity among older Brazilians. J Phys Act Health 2019;1-9 [Epub]. https://doi.org/10.1123/jpah.2017-0502.

Park CH. Experience of sport stacking in Korean older adults. J Exerc Rehabil 2017;13:43-47.

Park HW, Hong HD, Loet Leydesdorff. A comparison of the knowledgebased innovation systems in the economies of South Korea and the Netherlands using Triple Helix indicators. Scientometrics 2005;65:3-27.

Peterson MJ, Giuliani C, Morey MC, Pieper CF, Evenson KR, Mercer V, Cohen HJ, Visser M, Brach JS, Kritchevsky SB, Goodpaster BH, Rubin S, Satterfield S, Newman AB, Simonsick EM; Health, Aging and Body
Composition Study Research Group. Physical activity as a preventative factor for frailty: the health, aging, and body composition study. J Gerontol A Biol Sci Med Sci 2009;64:61-68.

Prochnow T, Delgado H, Patterson MS, Umstattd Meyer MR. Social network analysis in child and adolescent physical activity research: a systematic literature review. J Phys Act Health 2020;1-11 [Epub]. https:// doi.org/10.1123/jpah.2019-0350.

Roh SY. The effect of 12-week Pilates exercises on wellness in the elderly. J Exerc Rehabil 2016;12:119-123.

Sabot K, Wickremasinghe D, Blanchet K, Avan B, Schellenberg J. Use of social network analysis methods to study professional advice and performance among healthcare providers: a systematic view. Syst Rev 2017;6:208.

Sadria M, Karimi S, Layton AT. Network centrality analysis of eye-gaze data in autism spectrum disorder. Comput Biol Med 2019;111:103332.

Scott D, Daly RM, Sanders KM, Ebeling PR. Fall and fracture risk in sarcopenia and dynapenia with and without obesity: the role of lifestyle interventions. Curr Osteoporos Rep 2015;13:235-244.

Statistics Korea. Prospective population and household estimation [Internet]. Daejeon (Korea): Statics Korea; c2019 [cited 2019 Jul 19]. Available from: http://www.kostat.go.kr/.

Suh SR, Kim YM. Factors associated with physical activity of women aged over 75 in South Korea. J Exerc Rehabil 2018;14:387-393.

Taylor D, Myers SA, Clauset A, Porter MA, Mucha PJ. Eigenvector-based centrality measures for temporal networks. Multiscale Model Simul 2017;15:537-574. 